\title{
Narratives of Crisis: How Framing Urban Shrinkage and Depopulation Shapes Policy and Planning Responses in Spain, Germany and The Netherlands
}

\author{
Bozhidar Ivanov (D)
}

check for updates

Citation: Ivanov, B. Narratives of Crisis: How Framing Urban Shrinkage and Depopulation Shapes Policy and Planning Responses in Spain, Germany and The Netherlands. Sustainability 2021, 13, 11045. https:/ / doi.org/10.3390/su131911045

Academic Editors: Helen Mulligan, Karina Pallagst, Rene Fleschurz,

Thorsten Wiechmann,

Paulo Conceição and Miguel Amado

Received: 18 August 2021

Accepted: 3 October 2021

Published: 6 October 2021

Publisher's Note: MDPI stays neutral with regard to jurisdictional claims in published maps and institutional affiliations.

Copyright: (C) 2021 by the author. Licensee MDPI, Basel, Switzerland. This article is an open access article distributed under the terms and conditions of the Creative Commons Attribution (CC BY) license (https:// creativecommons.org/licenses/by/ $4.0 /)$.
Department International Planning Systems, Technische Universität Kaiserslautern, 67663 Kaiserslautern, Germany; bozhidar.ivanov@ru.uni-kl.de

\begin{abstract}
Academic research on urban shrinkage and depopulation has advanced significantly in recent years, mostly by attributing causality between the reasons and consequences of shrinkage in the positivist tradition of planning research. This paper critically analyzes shrinkage and depopulation as an issue of planning and policymaking in a broader institutional context. By applying a qualitative interpretive policy analysis methodology to planning and policy narratives from Spain, Germany and The Netherlands, this article highlights and scrutinizes how policymakers and planners have framed shrinkage, and how this framing has justified some of the selected planning and policy approaches. It is concluded that framing shrinkage in practice may only partially encompass the scientific definitions. It is also concluded that framing shrinkage and depopulation as a crisis may be determined by locally and temporally important issues as well as differences in planning cultures, which in practice may distance the understanding of the phenomenon from the scientific definitions. Debates on shrinkage conceptualization and the development of new planning concepts can become more applicable in practice by incorporating insights from qualitative investigations. This can bring them closer to planning practice and embed them in a wider planning system context, so as to produce more applicable and contextually sensitive proposals for addressing shrinkage.
\end{abstract}

Keywords: urban shrinkage; shrinking cities; urban planning; urban policy; planning systems; planning cultures; interpretive policy analysis; comparative urban research

\section{Introduction}

The research field of urban shrinkage has advanced significantly in recent years. With various theoretical and empirical contributions, urban shrinkage and shrinking cities have become a cornerstone in urban and planning research. Prior to reaching a scientific consensus of urban shrinkage as a complex phenomenon of urban change, the development trajectories of cities were viewed mostly from a political-economic standpoint. Kondratieff's view on the cyclical nature of economic development [1] and the theory proposed by Molotch for the city as a growth machine [2] have shaped earlier views on urban decline as a natural and temporary process that is strongly dependent on economic justifications. With recent advances in the field, especially after the fall of the Iron Curtain in Europe, extensive longitudinal research on the questions of urban population decline has contributed to advancing the understanding of these processes of urban change as a more complex phenomenon that goes beyond economic determinism. Seminal works, such as the Atlas of Shrinking Cities [3] have traced the phenomenon of urban population decline across the globe and have identified that various causes and trajectories of shrinkage occur in different settings. Cities may depopulate as a result of natural disasters, warfare and natural demographic processes, among others, in addition to the influence of major economic shifts. The timeline of change in cities may encompass longer periods of decline, followed by phases of growth [4], thus contributing to the economic perspective on urban shrinkage. 
The advances of globalization and its cultural and economic effects have also been associated with urban shrinkage and population decline across the globe $[5,6]$. The population dynamic, however, may also be indicative of long-term processes of demographic change that are inevitable or are less prone to being influenced by economic or other factors [7].

Recent advances in the field of urban shrinkage have examined the causes, consequences and solutions of the phenomenon. From a European perspective, demographic trends and migration have often been associated with urban shrinkage, especially when contrasting Eastern and Western Europe [8,9]. Embedding urban shrinkage in a broader demographic and geographical context has also expanded the scope of the phenomenon, since depopulation processes may encompass regions or whole countries. The reunification of Germany at the beginning of the 1990s brought this perspective of the phenomenon to the center of shrinkage research, with the massive migration waves that occurred within the unified country in parallel to economic decline [10]. The economic causes of urban shrinkage, mostly associated with deindustrialization in the West [11], were now accompanied by post-socialist transitions in Eastern Europe that had significant depopulation effects [12]. The research on post-socialist urban shrinkage similarly illustrated that the effects on cities go beyond population decline and result in diverse economic, social and physical consequences [13].

The field began to encompass also the effects of urban shrinkage by extensively examining the consequences of shrinkage and offering potential solutions [14]. Scientists review and suggest approaches to handling shrinkage-related issues, such as housing vacancy [15], brownfield vacancy [16], economic and spatial regeneration [17], and economic recovery [18]. Research in the field has often led to the formulation of recommendations and further discussions on possible ways of addressing shrinkage consequences. These discussions have been informed by a specific normative orientation of shrinkage strategiesaiming for overcoming shrinkage by pursuing regrowth [19] or accepting and managing shrinkage $[10,20,21]$. The illustrated development of the field has led to an unstable yet rich terrain of conceptualizations of shrinkage in academic debates.

These debates have attempted to universalize and structure rational and measurable criteria for urban shrinkage through the formulation of definitions. Urban shrinkage definitions have often encompassed a causal link between a specific reason for urban shrinkage, such as globalization or deindustrialization, and a number of consequences that can be observed in cities, such as depopulation and vacancy $[6,22]$. This has often led to viewing urban shrinkage as a distinguishable situation of a measurable crisis with different manifestations in specific cities. Conceptual discussions on defining urban shrinkage have had challenges identifying a specific set of indicators or characteristics that determine the phenomenon [23]. These attempts have greatly expanded the field and have contributed to a broader understanding of the phenomenon as part of academic debates. The theoretical reflections on defining shrinkage have also been used as a stepping stone for recommendations for handling shrinkage, as illustrated above. Conceptualizing urban shrinkage as a measurable and observable crisis that requires particular solutions has been solidified by a rationalist scientific approach to the question that has also triggered criticism. The attempts to rationally simplify and synthesize shrinkage have created challenges in comparative research and may have limited the possibility of advancing practically applicable approaches to it [24]. Attributing the causality of specific issues to urban shrinkage may have oversimplified their relationship since some issues that occur under conditions of urban shrinkage may also occur under conditions of growth [25]. These trends may have created an unnecessary exceptionalism of shrinking cities, thus further disconnecting them from questions of scale, such as regional processes, as well as from broader political and economic contexts [26]. In any case, population decline has remained at the center of the proposed conceptualizations but it has been accompanied by a variety of other topics and considerations [27]. Despite the over-inclusivity of the field, scientists have significantly advanced the conceptualization of urban shrinkage. The theoretical debates have led to the inclusion not only of objectively measurable phenomena of shrinkage in the definitions but 
also of soft factors, such as local politics, agendas and further contextual specifics [28-30] As illustrated also by previous research, the interpretation of urban shrinkage and depopulation by policy agents and planners may differ from the attempts of scientists to reach a universal definition. It is possible that shrinkage is, in planning and policymaking practice, closer to the "amorphous situation" referred to by Fischer [31] (p. 146) than to the "fuzzy concept" outlined by Olsen, echoing Markusen [29,32].

This article attempts to illustrate how urban shrinkage and depopulation have been interpreted in three distinctive contexts and across institutional scales. In order to illustrate this interpretation in practice, the article examines the process of framing urban shrinkage and depopulation. Subsequently, this paper traces how the framing of urban shrinkage and depopulation as a specific type of crisis, in the three distinctive contexts, is utilized as a justification for the selection of policy, planning approaches and solutions to the constellation of issues. The article argues that framing shrinkage as a crisis of specific nature is, in policy and planning practice, dependent on variations in planning cultures and planning systems. Omitting those differences and contextual specifics in theoretical debates on urban shrinkage may have negative effects on the practical applicability of suggested approaches to shrinkage and depopulation.

Firstly, in order to shift the focus from the spatial and measurable effects of shrinkage to interpretations and the formulation of meanings in planning and policymaking practice, this work proposes a qualitative interpretive methodology, in the tradition of interpretive policy analysis. Such a methodological approach counteracts the momentum of rationalization in the urban shrinkage field and contributes to a more critical perspective than the already available knowledge in the field. Secondly, taking into account criticism on urban shrinkage as being insufficiently integrated into local contexts and scales, the article explores approaches to depopulation from an urban planning and policymaking perspective by viewing the consequences or effects of population decline as a complex issue that involves various institutional levels across planning systems, rather than only as a problem of spatial or urban planning. By applying an interpretive policy analysis method to a broader set of planning and policy approaches, this paper attempts to "reconnect" the discussions on how shrinkage can be conceptualized back to practice. This would mean focusing not solely on the ex-post assessment, summarization and classification of specific effects and solutions to shrinkage, but on the ways that depopulation and its effects have been understood in the broader context of planning and policymaking in the respective contexts, and how this understanding has shaped the responses to them. Consequently, the scientific focus shifts from an emphasis on solutions to the broader process of the creation, justification and implementation of planning and policy responses, embedded in the context of various planning systems.

This approach is applied to policy and planning narratives from a period when addressing the consequences of urban shrinkage in Bilbao (Spain) and Leipzig (Germany) coincided with the stabilization or regrowth of the population. The topics of investigation are policy and planning attempts between the years 2000 and 2015, in both cases. Bilbao has been chosen as a representative case of post-industrial urban shrinkage, while Leipzig has been selected as an example of post-socialist urban shrinkage. These two types of urban shrinkage are representative of the varieties of the phenomenon in Europe [33]. In addition to those case studies, the third case represents a non-typical example of approaching depopulation-a proactive national and regional policy. The policy approaches to depopulation in The Netherlands, their anticipatory design and their application in the province of Zeeland after the year 2010, are a specific way of handling the challenges of depopulation from a broader policy perspective.

Shifting the focus from measuring and tracking the effects of shrinkage to formulations and interpretations of shrinkage as a broader policy and planning issue allows analysts to uncover the explicit or implicit frames, causal links, objectives, and interpretations of factors in the practices of planning and policymaking that form narratives of crisis and to juxtapose them with the causal links, introduced in the academic shrinkage conceptual- 
ization debates. Shifting scientific attention from evaluating and measuring the effects of shrinkage to critically examining interpretations of the phenomenon in a broader institutional framework contributes to bringing urban shrinkage scholarship closer to planning and policymaking practice. This contributes to the increased contextual sensitivity of urban shrinkage scholarship, as well as to debates on the normative orientation of shrinkage strategies and their potential for implementation in various planning systems.

\section{Methods}

The main method utilized for the proposed analysis is a variation of interpretive policy analysis, designed specifically for the purposes of a cross-national comparative planning study that has informed the results presented in this paper [34-37]. The design and selection of the method have been strongly informed by the works of Frank Fischer, John Forester, Martin Rein, Donald Schön and Deborah Stone. These authors have provided key contributions to the development of the field of interpretive policy analysis. One stepping-stone for the formation of the proposed method is the epistemological orientation of post-empiricism, also known as post-positivism, that considers reality as an observable phenomenon, parts of which are subject to objective analysis, but one that can never be fully explained or analyzed, given its social nature [31]. In the context of policy and planning responses to urban shrinkage and depopulation, this presupposition requires reflection and analysis of the meanings attributed by planners and policymakers to the issue they are attempting to solve, as well as to the desired effects of the proposed measures or approaches. This echoes the argument by Healey [38] that planning is ultimately a collaborative process between different actors that attribute different meanings and understandings to the object of planning (or the urban landscape). Additionally, Batty [39] argues for planning research that incorporates a more critical understanding of the urban landscape beyond the strictly rational tradition, one that also takes into account the social nature of the studied phenomena.

In order to identify how the shrinkage-related issues were understood and interpreted by policymakers and planners, the method attempts to identify three specific discursive elements as part of the analysis and to highlight the relationships among them. The first and most important element is the frame. As outlined by Fischer and Rein, and Schön [31,40], framing is one of the key cognitive processes that support the generation of meaning in the process of policymaking. It is the process through which policy agents attempt to make sense of "amorphous situations" [31] (p. 146). Therefore, the emphasis on framing urban shrinkage in practice may bring valuable insight as to how specific manifestations of shrinkage were understood and why a particular approach was chosen by the particular planners and policymakers.

This brings forward the second element of the proposed methodological approachthe identification of stories. Stone [41] defines stories as a key element in the formation of policy issues by policymakers. The story suggests that there is a choice that can be made to respond to a specific situation, as well as what the direction of this choice can be. Stories introduce the possibility of exerting control on reality by policymakers, thus justifying the very need for policy and planning. Stories are the discursive elements that introduce the notion of crisis and are particularly suitable for the perspective explored in this article-defining a policy problem as a crisis (of something) suggests that this crisis requires a solution and that the policymaker can provide it. One of the key examples that Stone gives is the particular story of decline used in policymaking - the story outlines a situation that gradually worsens over time, to an extent that becomes intolerable; thus, it has to be addressed. Stories are a vital part of the formation of policy and planning narratives and have influence not only on the formation of the understanding of the issue, thus complementing the framing, but also on the selection of responses to the issue being framed.

This brings forward the last element of the proposed method: the normative leap. The normative leap has been defined by Rein and Schön as the step from "is" to "ought" [40] 
(p. 148). It outlines the cognitive stage that follows the framing of the issue in the policy sense. The problem is understood in a certain way; it is framed to be a specific situation (as it is) and the remedy for it is supposed to change the situation in a specific way (as the situation ought to be). Normative leaps represent the essence of policy and planning measures and solutions; they often expose both the objectives of a certain measure and the desired effects of it. Therefore, they form an important component of a more nuanced analysis of urban shrinkage and depopulation in various contexts. Consequently, this contributes to a more critical analysis of the way that shrinkage and depopulation were understood, expanding the analysis beyond not only what the measures or approaches to shrinkage have been but also why those particular measures were chosen-bridging the gap with the framing processes that have been exposed with the other two discursive elements (frames and stories).

The proposed discursive elements of the frame, story and normative leap are identified in parallel as part of the analysis (Figure 1). As a result, the analysis exposes coherent interpretive constructs that have been identified in the respective policy and planning narratives. Policy and planning narratives are the main empirical data source for this paper. In a post-positivist sense, the narratives of reality are subject to scientific inquiry, and knowledge can be derived from them as part of the scientific inquiry [31,42].

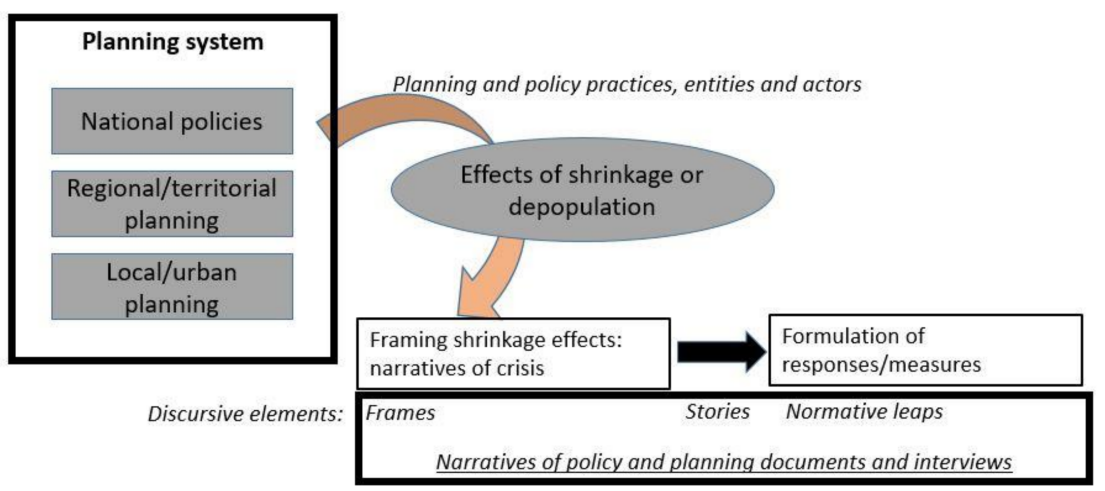

Figure 1. Visualization of the interpretive policy analysis method. Left to right and top to bottomplanning and policy practices, entities and actors on different levels of the planning system interpret the effects of shrinkage and depopulation and frame them in various narratives of crisis, represented by frames. The framing, represented by frames, determines the responses and measures, represented by normative leaps. Stories may connect the frames and normative leaps. The discursive elements are identified in the narratives of documents and interviews analyzed as the main source of empirical data. Interpretive constructs, consisting of those elements, are represented in the Results section.

The main source of empirical data for the narratives is selected policy and planning documents from various levels of the planning systems in the three selected cases, as well as interviews with policy and planning experts. For all three cases, some documents that are reviewed date from two or three years before the outlined timespans, due to the specifics of the approval processes or because they influenced the course of events during the period of interest. The document data has been collected from available public sources and official inquiries made with institutions in the period between May 2020 and April 2021. The data from documents has been processed with the MAXQDA software. Remote and face-to-face interviews with experts and politicians took place in June 2020 in The Netherlands, and between June and July 2021 in Germany and Spain. Field visits and observations took place in the same periods, respectively.

Since this paper attempts to examine the practices of planning and policymaking, the periods were chosen because of the accumulation of active attempts to address the consequences of urban shrinkage and depopulation. For the presented cases of Bilbao and Leipzig, the time span of interest is between 2000 and 2015. This period has been chosen as a turning point for both of the cities in question. For both cities, planning and 
policy efforts to address the consequences of shrinkage started before the year 2000 but continued afterward; thus, the period represents a timespan when the cumulative effects of long-term efforts can be traced in parallel with continuing measures in an already changing demographic setting. In the case of the province of Zeeland, the period chosen is between 2010 and 2020. In The Netherlands, the problem of depopulation is regional in nature and the measures to address it are being developed in a predominantly anticipatory manner. After 2010, depopulation in Zeeland began to be addressed gradually, while in parallel, further anticipatory measures were drafted.

Back in 1983, large-scale floods significantly affected the central parts of Bilbao (Figure 2). During the same decade, large sections of the industry moved out of the city or closed due to changing global economic conditions, leaving vast unused industrial spaces in the center of Bilbao. Starting in 1984, long-term efforts to decontaminate the Nervión river began and continued for many years ahead [43]. At the beginning of the 1990s, the political decision to build the Guggenheim Museum was taken and the museum itself was inaugurated in 1997 [44]. Bilbao continuously lost population throughout the 1990s (Table 1) and experienced vast spatial effects from industrial closure. Partial measures for urban regeneration began as early as the beginning of the 1990s, but shortly before and after the year 2000, the efforts of urban planning, policymaking and territorial planning began to overlap. This coincided with the gradual stabilization of the population of the city.

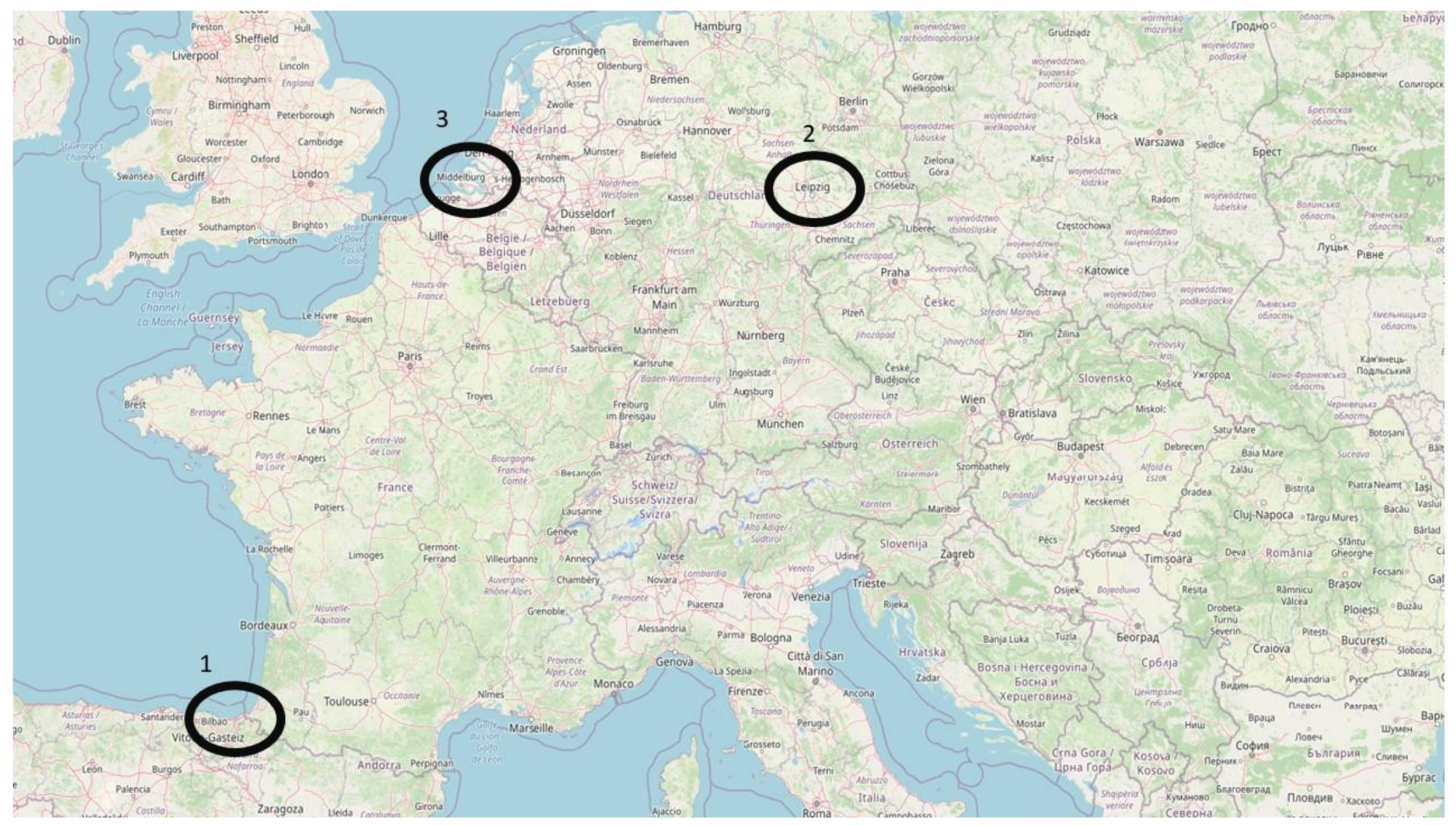

Figure 2. Map illustrating the locations of the selected cases. 1-Bilbao, 2-Leipzig, 3-Province of Zeeland.

Table 1. Population of Bilbao in selected years since 1991, illustrating the population loss and subsequent relative stabilization of the population. Source: EUSTAT.

\begin{tabular}{ccccccc}
\hline Year & $\mathbf{1 9 9 1}$ & $\mathbf{1 9 9 6}$ & $\mathbf{2 0 0 0}$ & $\mathbf{2 0 0 5}$ & $\mathbf{2 0 1 0}$ & $\mathbf{2 0 1 5}$ \\
\hline Population of Bilbao & 369,839 & 358,875 & 354,271 & 353,173 & 353,187 & 345,141 \\
\hline
\end{tabular}

Following the German reunification in 1990, Leipzig became part of the newly established federal state of Saxony (Figure 2). The eastern part of the country adopted the already established administrative and governance system from the west over the course 
of the 1990s. In a process similar to other post-socialist transitions, the eastern part of Germany and, respectively, Leipzig as a major urban center, experienced a shocking and fast economic, social and political upheaval with the adoption of a democratic system and market economy within a very short timeframe. The main difference in this context is that the former GDR became part of an already established democratic federal state, as opposed to other post-socialist countries in Eastern Europe, where those changes had to take place through a complete overhaul of the existing system from within. The opening up of the economy of the eastern part of the country to the globalizing international markets, ones to which the western part already had access, led to a rapid decrease in industrial activity in Leipzig and, consequently, to high unemployment rates. The possibility of migrating to the western part of the newly unified Germany allowed many citizens to move away. This opportunity, paired with lower fertility rates, exacerbated the population dynamic in Leipzig, thus further contributing to the depopulation of the city between 1990 and 2000 (Table 2). In parallel, during the 1990s, government subsidies for single-family housing led to an additional outmigration from the urban core to the neighboring areas [45]. Some key projects for the future of the city were also implemented throughout this period-the construction of the new fairgrounds, the establishment of a new industrial-business zone to the north, and the expansion of the Leipzig-Halle airport [46]. As can be seen by the nature of these projects, they were targeting competitiveness and the economic reinvention of the city, but this revival did not happen as fast as expected during the 1990s and coincided with the vast depopulation of Leipzig, leading also to significant land and housing vacancy. In this context, toward the year 2000, an administrative decision was taken to incorporate the settlements in the surrounding area of Leipzig back to the city. With the gradual realization that depopulation and urban shrinkage were happening not only in Leipzig but also in the eastern part of the country as a whole, the different levels of the planning system, as well as the federal government, gradually began to look for solutions. Thus, after the year 2000, various measures by urban planning, regional planning, federal and state policies began to work in parallel in Leipzig which coincided with the gradual increase of the population.

Table 2. Population of Leipzig in selected years since 1989, illustrating the scale of population loss and the subsequent increase in population. The spike in population numbers between 1998 and 2001 is as a result of the administrative expansion of the city. Source: City of Leipzig.

\begin{tabular}{ccccccc}
\hline Year & $\mathbf{1 9 8 9}$ & $\mathbf{1 9 9 8}$ & $\mathbf{2 0 0 1}$ & $\mathbf{2 0 0 5}$ & $\mathbf{2 0 1 0}$ & $\mathbf{2 0 1 5}$ \\
\hline Population of Leipzig & 530,010 & 437,101 & 493,208 & 498,491 & 522,883 & 560,472 \\
\hline
\end{tabular}

Population decline and consequent urban shrinkage are rather an exception in The Netherlands. As of 2021, the country's population is steadily growing, and government policies are focused on facilitating this growth. Nevertheless, some border areas of the country have been experiencing population decline for some years; this has led to various policy and planning efforts that have been subject to investigation [47,48]. The researched examples of shrinking cities in The Netherlands are usually part of a wider area that is losing its population. Zeeland is a province of The Netherlands, located in the southwestern part of the country, bordering Belgium (Figure 2). Geographically, the province is unique as it is located on the delta of the Scheldt river, exposed to the North Sea. Historically, the province consisted of a number of separate islands that were connected to the mainland through land reclamation efforts, as well as the massive engineering solution of Delta Works, built as a protective barrier after the devastating flood of 1953. The geographical characteristics of the province are an important consideration regarding the nature of the depopulation phenomenon there. Firstly, the province is somewhat isolated from the rest of the country. Secondly, the population within the province is unequally spread in small settlements across the former island areas, as well as in the isolated region of Zeelandic Flanders, on the border with Belgium. Zeelandic Flanders is one of the regions within the province that already experiences depopulation. It is detached from the rest of the province 
and thus the country, and is connected with them through an underwater tunnel and a pedestrian ferry. Zeeland as a whole is expected to depopulate in the long term (Table 3). In that context, the provincial administration of Zeeland has to facilitate the depopulation policy by balancing specific regional characteristics as well as maintaining a larger-scale view of the governance of the whole province. The questions of depopulation and urban shrinkage, as well as all policy efforts for them, developed gradually in The Netherlands after the year 2010 when various scientific reports highlighted the demographic trends in the regions in question [49]. In that sense, the Dutch context is in a more favorable position than that of other European countries, especially in Eastern Europe, where depopulation processes are much more severe and are rapidly unfolding.

Table 3. Population of Zeeland between 2015 and 2020. Population growth is slowing down and is forecasted to decline in upcoming years. Source: CBS Netherlands.

\begin{tabular}{ccccccc}
\hline Year & $\mathbf{2 0 1 5}$ & $\mathbf{2 0 1 6}$ & $\mathbf{2 0 1 7}$ & $\mathbf{2 0 1 8}$ & $\mathbf{2 0 1 9}$ & $\mathbf{2 0 2 0}$ \\
\hline $\begin{array}{c}\text { Population of the } \\
\text { province of Zeeland }\end{array}$ & 380,726 & 381,252 & 381,568 & 382,304 & 383,073 & 383,488 \\
\hline
\end{tabular}

The three cases in this article have comparable population thresholds (between 300,000 and 600,000 ), which allows a comparison between urban and regional planning and policy efforts in various planning settings.

\section{Results}

3.1. Bilbao

\subsubsection{Planning System Characteristics}

Bilbao's transformation has been a long-term process, starting back in the 1980s. Its development has been influenced strongly by the establishment of planning processes in the autonomous community of the Basque Country, where Bilbao is located. The 1978 constitution, establishing the democratic foundations of modern Spain, provided different regimes of autonomy for the 17 autonomous communities in Spain. The overall territorial planning and the related planning system structures were delegated to the competence of each autonomous government except in those matters that transcend the community borders, such as airspace and coastal management, among others. As a result, in the 1980s, the Basque Country had to gradually establish the necessary administrative, legal and procedural competencies in order to manage its territory and, consequently, its cities. Additionally, the Basque Country's statute of autonomy also allows it to pursue a separate tax policy and an almost independent economic policy from the rest of Spain [50]. The processes of establishing the abovementioned competencies took longer than expected and left long periods of planning and legislative voids. The law of territorial ordinance of the Basque Country was not approved until 1990, while a follow-up law for land and urbanism was approved in 2006. A quasi-regulatory quasi-strategic document was approved on the level of the autonomous community in 1997-the directives for territorial ordinance. On an urban level, the preliminary outline of Bilbao's general plan ("Avance", in Spanish) was published in 1989, but the plan itself only came into effect 6 years later, in 1995. This timeframe coincided with the urban shrinkage processes in Bilbao, as well as with the aftermath of other spatial and environmental events that have influenced the city's trajectory. This background overview is important in order to illustrate the context of the changes that took place, as well as to show that toward the end of the 1990s, the city reached a tipping point in the establishment of planning processes and their implementation. The planning and policymaking processes that have been reviewed encompass the territorial planning of the Basque Country at the level of the autonomous community, the metropolitan-level planning of the area of Bilbao, and the local level of urban planning. The latter two involve a fragmented landscape of strategic planning and executive agencies and departments with clearly defined responsibilities. 


\subsubsection{Bilbao's Urban Shrinkage as an Economic Transition and Spatial Crisis}

The interpretation, framing and approach to the changes taking place in Bilbao in the context of the Basque Country rely heavily on the intertwined perspectives of economy and space. The 1997 directives of territorial ordinance of the Basque Country illustrate these frames with an overview of the economic transition taking place in the autonomous community. The primacy of the industrial past of the region is interpreted as the main driver of the migratory, territorial and social development of the whole community. The main frame in this context is introduced with the notion of industrial decline, understood as an impactful process to the whole community and, respectively, to its urban cores, areas that were previously central locations of economic and social concentration and are now losing their importance, due to the economic changes taking place. The process is framed as a "rupture" of the associated territorial development of the community, leading to an outmigration from the urban cores as a result of a significant economic transition. The territorial perspective then proceeds to identify opportunities for a more balanced territorial development of the autonomous community, stepping onto economic and territorial models.

At a local level in Bilbao, similar frames, complemented by stories, are being used. In interviews with planners and policy experts of the city, there is a remarkable consistency in the way that the changes in the city are explained. The key role of Bilbao in its industrial heyday is contrasted to the gradual decline of industry in the late twentieth century. Industrial decline is framed as the major economic process taking place but, in the context of the city, its spatial effects are outlined on a par with its economic and social challenges. The economic downturn is associated with outmigration from the historic city core that was additionally worsened by the floods, affecting mostly the historic old town. Outmigration is also contextualized in the broader Spanish context as industrial Bilbao attracted many workers from the rest of the country. The effects on the remaining population are framed again from an economic standpoint, as high unemployment rates. The spatial effects of those changes are framed with an emphasis on the centrality of the former industrial areas in the city-close to the river and in an attractive space at the center of Bilbao. The gradual closure or relocation of those industries (to the outer port on the Atlantic coast) leaves vast industrial spaces obsolete. This is usually the accent of the frame or story that explores the spatial effects of the industrial transition. Particular emphasis in this regard is placed on the areas of Abandoibarra and Zorrotzaurre, which were the main industrial and port zones of the city. In addition to the framing of this spatial crisis, the development of the former workers' neighborhood of Bilbao La Vieja is also associated with the economic downturn - the outmigration there is interpreted as the main reason for the long-term social issues and lower quality of life in the area. The overall changes in the city in that period are interpreted as negatively affecting its image, thus rendering it unattractive as a place to live.

In the planning documents at a local level, the emphasis of the frames about the city's transformation is mostly placed on the economic aspect and not as much on the spatial one. The partial territorial plan of the city from 2006, for example, frames the negative spatial effects of the economic transformation as only being partially overcome, referring to the vast, obsolete industrial areas. The available space is framed as a resource that can be explored as a new basis for economic activity in the city. The emphasis on the economic transition from an industrial to a service-oriented city is prominently placed as a story of change. On the level of specific areas, the area of Zorrotzaurre, for instance, is framed as a problematic environment comprising a small amount of active industrial spaces, together with a number of obsolete buildings of lower quality. From an economic perspective, the same plan from 2006 negatively frames the insufficient number of new firms being opened in the city. This predominantly economic perspective is complemented by certain documents, the product of strategic reflections between companies and the public administration in Bilbao's metropolitan area. The main stories outlined in those 
strategic documents after the year 1999 emphasize the endogenous economic potential of the city, framed as a likely source of future competitiveness for the area.

The economic-spatial intersection of the frames and stories remains central in the formation of the normative leaps that justify the respective measures and interventions after the year 2000, but it is complemented by a number of objectives and goals that do not necessarily correspond to a specific frame or story of a crisis or problem. On the level of territorial planning in the Basque country, the centrality and importance of designating space for economic activities are highlighted as an activity of "undoubted general interest"; thus, any intervention in allocating such a space is deemed to be necessary and important. On a local level, the economic-spatial dimension of framing corresponds consistently with the normative leaps placed on the regeneration of the central areas of Abandoibarra and Zorrotzaurre, for instance. The planning experts' points of view reveal that the overall projects for those spaces serve the goal of creating new points of economic activity in the actual city. Additionally, the projects there contribute to other economic goals, such as enabling the human capital of the city (through universities and technological centers) and projecting the city's image internationally, resulting in mass or congress tourism. From this economic perspective, the framing and the normative leaps show consistency.

However, the expert point of view also reveals that these objectives are far from the only ones that were established when the various interventions were designed. The area of Abandoibarra, where the main promenade and the Guggenheim Museum are located, was previously significantly contaminated and was predominantly industrial. The completion of the project after the year 2000 is considered as an intervention in the central zones that has contributed to an overall improvement in the quality of life for the citizens of the whole city, since the area has been effectively reclaimed as a predominantly public space of high quality, with innovative urban design and architecture. The project is viewed as a sustainable urbanization intervention as it reuses the available space successfully. Similarly, the second large-scale project-the area of Zorrotzaurre that is currently being regenerated-will also transform a predominantly industrial area into a mixed-use zone of residential, commercial and public spaces. Local experts positively evaluate the approach to Zorrotzaurre, highlighting the fact that the authorities of the city have acquired knowledge and confidence in managing such large-scale interventions. In their view, this has been complemented by positive evaluations by citizens and increased trust in the authorities' delivery of the projects, as well as higher expectations. Particularly in the case of Zorrotzaurre, a significant part of the project is dedicated to residential housing for private and protected-price controlled use. This element of the project is envisioned by experts as a way to regain the population lost in the suburbanization processes of the last 30 years, as well as to meet the increased demand in the city from a current perspective.

Apart from those two key central zones, the planning experts also highlight that, as part of the overall effort to improve the quality of life in the city, a number of interventions were also implemented in certain neighborhoods in Bilbao, for many of which specific area plans have been developed. Examples are the rehabilitation measures in the previously mentioned area of Bilbao La Vieja, as well as the area of Miribilla. Another example is the regrading and leveling of the former railway trenches, such as the Ametzola area, thus further densifying and transforming a former railway area into a park and public space. The effects of investments in mixed-use, improved public infrastructure and pedestrianfriendly developments have been observed in those areas during field visits by the author. Experts from different institutions and agencies share the understanding that there was a need to regain the quality of life in the city in order to make it an attractive place to live; however, this was not an easy task, due to the constant tension between the considerations of economic feasibility in terms of investments and their effects on the quality of life. 


\subsection{Leipzig}

\subsubsection{Planning System Characteristics}

The German planning system is robustly structured and has a clear, albeit complex, distribution of responsibilities [51]. The federal states have a certain level of autonomous decision-making but there is also significant dependence on the federal government-this was especially valid in the eastern federal states, following the reunification. Thus, the main levels of the planning system that shape the planning and policy efforts in Leipzig, as of the year 2000, are the German federal government, the State of Saxony, the regional planning authority of Western Saxony, and the city of Leipzig itself. The various policy and planning efforts originate, are coordinated by, or involve various institutional actors across these levels of the planning system and were the focus of the empirical work for this case study.

\subsubsection{Leipzig's Urban Shrinkage: Housing and Spatial Crises and Attempts at Control}

The main frames of the urban shrinkage processes in Leipzig are related to the unsatisfactory characteristics of various policy areas, as a result of demographic dynamics. The interpretation of the phenomenon usually stems from a reference to negative demographic development (depopulation) that subsequently has implications on other policy and planning areas, thus creating the need for intervention. Quite often, this frame is complemented by another one about housing - either concerning vacancy or lower quality. For instance, the Urban Redevelopment East (Stadtumbau Ost) program, one of the main federal instruments for investment and urban renewal, effectively considers urban shrinkage as a demographically driven process of depopulation that creates a critical situation of housing conditions as well as vacancy, and it is particularly visible in specific areas of cities. At a state level in Saxony, policy documents reveal a similar frame-irreversible demographic trends of depopulation having an impact on urban development within the federal state, as well as the housing market, the economy, infrastructure, and services. At a regional level, in the West Saxony regional plans, the urban shrinkage processes are framed as a functional crisis - central cities, such as Leipzig, have a role to play in the supply of services for specific regions and may be unable to continue performing this function. In this particular frame, the emphasis is not on the demographic processes, but rather on the spatial dimension - the expansion of commercial locations or other service areas outside of the urban cores is framed as being undesired.

The various local plans of Leipzig between the years 2000 and 2015 frame shrinkage in a number of ways. The major planning efforts in the city in this period are twofold-the urban development plan (Stadtentwicklungsplan-STEP) circa 2000, and the urban development concept (Stadtentwicklungskonzept-SEKO) from 2010. Central topics throughout the period remain land use and housing vacancy. In the urban plans from between 1999 and 2005 (part of the STEP planning effort), land vacancy is framed as an undesirable spatial condition with important potential for future commercial development within the city, due to the favorable location and infrastructure provisioning of the lots. Specific emphasis is placed on the challenges associated with the private ownership of these vast formerly industrial sites. Years later, in the next round of plans (SEKO), the land vacancy was still framed as an unresolved issue, although it was subject to a number of interventions. In 2021, vast unused vacant spaces are still available in the city, as confirmed by observations in the area of Leipzig-Plagwitz.

The second main frame utilized at a local level concerns housing and the handling of housing vacancy. The frame in the plans highlights varied development in different parts of the city, leading to market distortions, further housing vacancy and lower quality of life. In the earlier plans from 2002, particular emphasis was placed on the indebted housing companies and the unfavorable effects of housing vacancy on their operations. This risk is paired with the market challenges for private owners, unable to maintain or offer their properties on the real estate market. In the plans made after the year 2010, the issue with 
vacancy remains framed as a challenge but with an emphasis on specific areas in the city, such as Grünau and Leipziger Osten.

The differentiation of the characteristics of various parts of the city remains in the frames, related to the economic development of the city as well. In the earlier plans, the need for economic development is framed as important for the whole city. In the later plans, when the city's economic trajectory had already begun to improve, the economic development is already framed positively but is paired with remaining unemployment issues only in specific districts. In addition to those differences, social issues, such as persisting social segregation and social support provisioning, are framed again as problems in specific districts within the city. Framing those issues as district-specific is also shared across policy documents at both state and federal levels.

A story of control, remedy and action consistently establishes the link between the frames illustrated above and the measures that need to be taken. This story can be found in documents across the various levels of the planning system. On the upper planning levels, the framing of shrinkage as an irreversible demographic-driven process with a negative impact on cities leads to the normative leap of the need for integrated concepts of urban development-a requirement of the Urban Redevelopment East program, in order to provide funding. The development of those concepts is seen as necessary, due to the challenging nature of the phenomenon, as well as a chance to approach the urban dimension of the issue in a holistic way. This normative leap is supported by a somewhat hidden frame-that of framing the shrinkage crisis as an opportunity. This way, the measures of the program are seen as a chance to improve living conditions in the specific areas, as well as to generally contribute to more attractive and livable cities. The aboveillustrated story of control, and the normative leap on the holistic approach, correspond well to the normative leap pertaining to land vacancy - the lower demand from investors is seen as a need to explore other ways to manage vacancy, such as temporary uses, proactive marketing by the city, and the general readiness of the local administration to experiment with innovative planning instruments. The latter understanding is also shared by planning experts in the area of Plagwitz. In their view, during the shrinkage period, the vacant land was so great that openness for experimenting was expected of the administration, given the readiness of the citizens to attempt such experimentation.

The normative leaps in two categories remain intriguing. The issues with housing, framed as an impending and critical crisis in the earlier plans, lead to the firm normative leap of necessary intervention in the housing market through restructuring, reduction and market segmentation. As illustrated in the housing policy of the city from 2002: "The negative cycle must be broken by reducing the housing stock [ . . ] in all market segments". Later on, this would lead to the positive framing of a stabilized housing market in the plans from 2010. Secondly, the framing of social and economic issues, together with urban and spatial ones, in specific districts of Leipzig, such as Leipziger Osten, leads to an unclear normative leap on continuing urban development measures for the area. Despite the various interventions from the city there, the concept plan for the area from 2013 still highlights ongoing social challenges. The plans, however, appear to be persistent in demanding urban and spatial measures for clearly articulated social issues. This perspective creates friction with the view shared by the Saxon Ministry for regional development, responsible for the coordination of another federal program-the Socially Integrative City (Soziale Stadt). The ministry also views the same social issues as district-specific; however, the normative leap associated with this understanding is that those social issues cannot be resolved solely with urban redevelopment measures, thus justifying the need for the program itself as a bridge between social and urban measures for challenging areas. 


\subsection{Depopulation in The Netherlands and in the Province of Zeeland}

\subsubsection{Planning System Characteristics}

Depopulation is broadly viewed as a regional phenomenon in The Netherlands. Regions, however, are not specific administrative structures. They are geographic and statistical subdivisions of the provinces of The Netherlands. The provinces themselves have a certain level of autonomous governance, with democratically elected institutions. At the same time, municipalities are more dependent on the government than on the province, as they receive the majority of their funding from central government transfers [52]. This creates a peculiar setting for approaching the phenomenon of depopulation in The Netherlands-specific parts of the border areas are losing or are expected to lose their populations; the towns located in those areas are also affected by those processes but, with the phenomenon being regional in nature, the issues cannot be approached solely from an urban level, nor entirely from a provincial level.

In the strict and plan-led structure of the planning system of The Netherlands [51], depopulation is still a fairly exceptional phenomenon at a regional level. The three main levels of the planning system - national, provincial and municipal—work together to approach it. The national approach to the question of depopulation classified specific regions as already depopulating or anticipating depopulation. In this classification, Zeeland's regions of Schouwen-Duiveland and Walcheren are classified as anticipating depopulation, while Zeelandic Flanders is classified as already depopulating. At a provincial level, Zeeland's population is expected to stabilize in the short term and gradually decline in the long term. This approach to depopulation in The Netherlands is a specific case that involves an anticipatory cross-cutting policy approach from national to provincial and local levels. The distinction between national and provincial levels is sustained in the presentation of the results.

3.3.2. Regional Depopulation in The Netherlands and Zeeland: Threat to the Economy and Livability

One specific aspect of the framing of the phenomenon in The Netherlands is that the terms "shrinkage" and "depopulation" are used interchangeably. It is possible that this has implications for the way that depopulation/shrinkage is viewed from a policy perspective. Depopulation or shrinkage, framed as a demographically driven, inevitable process of losing population in specific regions, is interpreted as a cross-cutting phenomenon that has implications for various policy areas. Particular emphasis is placed on the implications of depopulation for local and regional economies, the provisioning of services (such as social care and education), housing market dynamics, and, as a consequence of all of the above, an overall decrease in quality of life in these regions. The understanding that depopulation dynamics have implications in various policy and planning fields implies that this change requires a coordinated policy approach. At the same time, there is an overemphasis on the demographic nature of the phenomenon; thus, population numbers and structure are the key indicators behind the change. This particular understanding introduces the various frames utilized to outline why a decrease in population is threatening to a specific policy field. For instance, from an economic standpoint, depopulation is framed as affecting the labor market in the depopulating regions. Consequently, the frame continues, a vulnerable labor market can have negative effects on economic growth. From the perspective of the provisioning of services, an emphasis is placed on age-specific services, such as healthcare and education, where demand and quality are framed as being impacted by the changing population structure of the respective region. The frame utilized for the housing market outlines the mismatch between supply and demand for housing as an undesirable development of the market. An additional perspective in this topic is introduced via the risk of the decreasing quality of housing due to the lower maintenance of vacant homes, as well as the compromised future condition and preparedness of the housing units. 
The frames of housing vacancy and lower service levels overlap in the frame of decreasing livability. This understanding appears to be very noticeable across various policy documents, as well as from the point of view of national and provincial experts. The understanding of livability (a loose translation of the Dutch term, "leefbaarheid") can be found in the narratives of both policy documents and expert evaluations. This concept stipulates an understanding of a specific set of characteristics and services in a living environment that need to be maintained, in order for it to be considered a pleasant, attractive and desirable place to live. One of the national experts on depopulation refers to the provision of these standards on an equal level across the country as being a constitutional right. In this respect, policy toward the consequences of depopulation needs to be proactive, lest the livability be compromised by the changing conditions.

At a provincial level in Zeeland, the understanding of depopulation and shrinkage as one and the same demographic phenomenon is also present. It is framed as a cross-cutting characteristic of the population structure and dynamic of the province, with implications for various areas. This understanding is also used to justify the regional policy approach, necessitating cooperation between municipalities as well as across planning system levels. Both of those frames illustrate a remarkable consistency of understanding of the phenomenon between the national and provincial levels, as well as consistency in the overall policy approach. Additionally, the concept of livability remains a central frame in the provincial understanding of depopulation. The provincial strategies and documents view Zeeland as a place with very good living conditions that are threatened by depopulation. Interestingly, the livability frame is expanded beyond the standard reference to good living conditions and is tied to the economic performance of the province. The economic conditions in the province are framed as a main contributor to the level of prosperity of its citizens. Hence, depopulation is also framed as a risk to the economy of the province, from the perspective of labor market shortages and an unfavorable business climate. The importance of those economic frames is on a par with the livability perspective in the various policy documents from the province. The experts' points of view reveal additional implications for the frames of livability, the economy and service provisioning. Housing vacancy and low maintenance are framed as undesirable in the context of neighborhood livability. The provisioning of services is also framed as challenging, both from an efficiency perspective and from a financial perspective. For example, the transport services within the province, as well as the school infrastructure, are currently a challenge due to the decreasing population. The economic condition is framed as vulnerable from the perspective of labor market shortages and negative image. The planning experts' points of view reveal a good level of consistency in their understanding of the phenomenon and its implications in the province.

The above-illustrated frames consistently justify the normative leaps in the formulation of measures on both national and provincial levels. The emphasis on measures and their objectives is similar to the one in the frames, addressing most importantly the economic perspective, the quality of life dimension and the housing market. The economic objectives of the measures attempt to find ways to avoid or mitigate the labor market mismatch. One example of such a measure is the close cooperation between local businesses and educational facilities to plan training programs that may qualify future employees for local needs. This is complemented by efforts in sustaining or improving the image of the province of Zeeland as a good place to live and operate businesses. These efforts serve an objective that is only partially made explicit by policy documents or expert points of view - the need for and importance of sustaining the existing economic base of the province. Zeeland is home to several large multinational companies in the chemical industry, has strong port and energy production infrastructures, and is a popular tourism destination. Those main economic branches are seen as key to the characteristics of the province; in that respect, the objectives of the economic measures in the context of shrinkage are oriented toward eliminating any risks to those industries. The importance of the economy is on a level playing field with the need to sustain good livability. The objectives in this area are usually linked to the housing measures. Specific financial and planning instruments 
that support demolition, renovations, or nearby parcel mergers have been introduced at a provincial level. Those measures are justified by the objective of sustaining the quality of life, even at a small-scale neighborhood level. The planning experts from the province illustrate the effectiveness of these measures with the example of citizens who are not satisfied with living near vacant housing. Thus, the said instruments are designed to support citizens in acquiring nearby privately owned plots and either renovating or demolishing the house. This variation of resizing the housing market corresponds to the other objective articulated clearly at national and provincial levels- the need to control the housing market and to intervene to ensure quality and consistency between supply and demand. This objective is justified by the undesirable effects of the devaluation of housing, which can threaten a well-functioning housing market. The housing-livability pair of objectives is also complemented by the need for "future-proof" housing - a forward-looking normative orientation, outlined at both national and provincial levels, that housing units need to be able to respond to future changing conditions, such as climate change, but also as a stipulation of the need for high-quality housing in the long term.

Lastly, the illustrated framing and normative leaps in The Netherlands and Zeeland are supported by a consistent story that is shared at both national and provincial levelsviewing depopulation and shrinkage as an opportunity. The notion of accepting population decline and viewing it as a chance for improvement was found on several occasions in policies and in expert interviews. In a similar vein, some policy documents reflect on the processes of depopulation as "becoming normal", not necessarily affecting prosperity, opening space for experimentation, and overcoming the "traditional" growth orientation in terms of building and population. One planning expert refers to this way of thinking as "shrinking smart".

\subsection{The Unexpected Crisis: The COVID-19 Pandemic}

Since the empirical work for this research was performed during the global COVID-19 pandemic, this topic appeared spontaneously in the conversations with experts in all three cases. Although not a particular focus of this research, it is worth mentioning how the experience of approaching shrinkage has influenced their view on the ongoing effects of the pandemic.

In Bilbao, the strong dependence on mass and congress tourism is now challenged by disrupted traveling patterns as a result of the pandemic. The local experts are hopeful that this problem will be overcome soon.

In Leipzig, the pandemic and its effects on the city are seen as an unexpected planning challenge, despite the continuous improvement and adaptability of the local planning practice. Local planners are surprised by the need to shift the focus to the immediate living environment, with more people staying at home or in their neighborhood. The event is viewed as an unexpected societal disruption for which planning has not been prepared. Ministry experts share a similar perspective.

A more hopeful view of the pandemic was shared by the respondents in The Netherlands. From the perspective of Zeeland, the changing work-life patterns of the pandemic, with the increased possibility of working from home, were viewed as a chance to offer a new home to digital or remote workers. The good living conditions of the region are viewed as a particular benefit in this regard. The pandemic period is seen as a chance to invest more in the connectivity infrastructure so as to enable digital solutions for ongoing challenges, such as schooling and education.

\section{Discussion}

The interpretive analysis of policymaking and planning efforts in the reviewed cases illustrates that in planning and policymaking practice, the conceptualization of shrinkage is dependent on a variety of frames that interpret the associated effects as crises of a specific nature. This framing only partially overlaps with the scientific definitions of shrinkage. The definition proposed by Martinez-Fernandez et al. [6], for instance, encompasses numerous 
facets of the urban shrinkage phenomenon-geographic, social, physical, demographic, and economic. Comparing this definition to the illustrated framing of shrinkage in the three cases above shows that, in practice, the understanding of shrinkage rarely encompasses all of those aspects and is seldom seen to be such a complex phenomenon as is usually presented in academic debate. The predominant interpretation in the case of Bilbao is focused on the economic and spatial consequences of the phenomenon. In the case of Leipzig, the main frames point to housing and land vacancy. In Zeeland, the frames introduce risks regarding livability and economic development. Thus, if the concept of shrinkage is expected to inform recommendations for approaching shrinkage or depopulation, the phenomenon can be viewed more as a spectrum of a variety of effects that may be interpreted differently, depending on the context, rather than as a fixed set of indicators.

It appears also that the causal interpretations vary significantly across the investigated cases. In the case of Bilbao, for example, it is clear that the challenges that the city faced were mostly understood as being associated with an economic transition on a broader scale. This finding aligns with the conclusions of Gonzalez with regard to the scalar narratives in Bilbao's approach [53]. Consequently, the centrality of the economy remained as one of the main justifications for urban regeneration efforts. To a certain extent, the economy obscured other topics in the planning and policy documents, but it did not necessarily compromise the efforts made in planning practice in other areas, such as quality of life. Similarly, regional depopulation and its effects on the towns of Zeeland is viewed as threatening to the stable and favorable economic base of the whole province; thus, the measures at a provincial level targeted the economy as a whole. The way that the issues are framed and understood by policy and planning practitioners has had an influence on the selection and design of responses to urban shrinkage or depopulation. The policy and planning justifications outlined in the results illustrate a more nuanced picture of the usual causes-consequences-solutions axis of urban shrinkage definitions that may be indicative of a conceptual elasticity of the shrinkage definitions. It appears that in planning and policy practice, less complex causal relationships are enough to justify a specific approach. In addition, there appears to be a stronger influence of contextual factors, where locally and temporally important topics determine the desired and undesired trajectories of development that influence the objectives. This corresponds to some of the conclusions from previous studies exploring how political, contextual and institutional factors influence the shrinkage agenda and, thus, the approaches to it [28,30].

This more nuanced understanding of urban shrinkage and depopulation also highlights the fact that narratives of crisis associated with these phenomena may vary across different contexts. Urban shrinkage has hardly been interpreted as a crisis narrative on its own (as experiencing "urban shrinkage"), but rather as a crisis of specific sectors and policy or planning areas. These frames were influenced by what was considered as being important at a specific moment of time, as well as in a specific context. This is quite noticeable in all three examples above, but it is most visible in the case of Leipzig and the impact of depopulation on the housing market. The effects on the housing market have been framed as critical, thus providing a justification for planning intervention. This echoes the observations by Bernt on the condition of the housing market in Germany in the same period, and the active policy to resize and intervene in it [54]. The emphasis on housing is also indicative of planning culture specifics, explored later in this section. Another example is the social issues, formulated consistently in various plans in Leipzig. The identified persistence of these issues across time, and the expert assessment of the question, indicate that long-term social issues may need to be approached not only with urban or spatial planning measures but also with tailor-made policies. This shows that the challenges associated with shrinkage and depopulation may surpass the strictly urban scale and may require the involvement of various planning and policy levels. This would signify a crisis that may also exceed the scope of planning and may require much more complex approaches to social issues on a larger scale. 
The analysis of normative leaps exposes the normative orientation of certain measures and objectives, as related to the framing of the phenomenon and its effects. These observations contribute to the distinctions between strategies that aim to regrow shrinking cities versus strategies that accept and manage shrinkage (or do not aim for growth). [14,55]. The analyzed examples illustrate that this clear-cut distinction is not as pronounced in practice. In fact, the interpretive analysis shows that there is no indication of a holistic understanding of exclusively pro-growth or non-growth-oriented efforts. The strategies or approaches to shrinkage in the investigated examples encompass multiple policy areas, and there may be different objectives in each of those. This can be observed in the distinctions between space, economy and population. Bilbao, for instance, has pursued a strategy of economic growth and competitiveness, and this has been clearly formulated across various policy and planning documents, as well as in conversations with experts. Its spatial development, however, does not appear to have pursued growth in any way. Although the city has invested significantly in its transport infrastructure to facilitate connection with the nearby municipalities, thus achieving a level of metropolitanization, the analyzed empirical data shows that it had not formulated or considered an objective or strategy regarding spatial expansion. This may be related to the topographical limits of the city, due to its location in a river valley but, in any case, the normative leap analysis illustrates that the interventions in the central areas as well as on the periphery have attempted to further densify and utilize the available space, thus avoiding expansion.

In a similar vein, Leipzig's attempts to utilize the available land vacancy within the city limits after the year 2000 comes after a period of unsuccessful spatial expansion that started at the beginning of the 1990s. Although it is not clear whether there was a specific objective in the desired expansion back then, after 2000 it is clearly stipulated, across various policies and plans, that Leipzig needs to focus on the available space. The economic orientation at that point, however, has not been articulated as being undesirable or directed toward anything else but improved competitiveness. The efforts of the local authorities to market the available land and to attract large-scale investors to the city have been oriented to economic growth. This confirms the observations in previous research on Leipzig's trajectory toward regrowth [56]. The distinction of frames and objectives in spatial and economic terms can be observed, and it can be concluded that they do not necessarily match and may pursue different effects. An economic growth orientation in a compact spatial form, as has been the case for both cities, would align them with the hypothesis of smart growth, where the focus is to contain and properly direct new investment spatially $[57,58]$.

The results also illustrate the normative orientation of the policy and planning measures in terms of considerations of quality of life. In Bilbao, measures for improving the quality of life in the city as a whole have been clearly translated via meticulous technical requirements stipulated in the city master plan. The designs of the regeneration projects have included considerations for mixed-use public space, affordable housing, and greening. The expert assessment of planning approaches at city and area levels confirms that there is a well-grounded consideration of quality-of-life perspectives in the planning practice of the city that has not been compromised by the orientation toward economic competitiveness. In the case of Leipzig, the quality of life objectives and normative stances are more clearly articulated in the planning and policy documents. They are formulated in the context of overall orientation toward improvement in urban livability. Similarly, livability considerations in the Dutch context appeal to a set of living standards that need to be maintained. The German and the Dutch examples may be indicative of a stronger tradition or more established ideals of quality of life, influenced by planning culture and materializing in urban spaces [59]. These observations may also be indicative of the possibility of framing shrinkage as an opportunity to experiment with non-traditional planning approaches that can contribute to improvements in livability and quality of life. Some elements of framing a crisis as an opportunity can also be noticed in the experts' points of view with regard to the COVID-19 pandemic. 
Differences in planning cultures can also be observed in another two of the conclusions from Germany and The Netherlands. Firstly, the idea of establishing control and clearly articulating planning and policy objectives can be found in both cities. The plans and policies explicitly formulate the desired outcome of each measure or proposed approach. This can be observed in the story element in the case of Leipzig where, on various levels of the planning system, not only the objectives of specific measures are stipulated but also the need for very particular planning approaches or instruments. For instance, the integrated urban development concepts that were stipulated as a requirement at a federal level through the Urban Redevelopment East program were also highlighted as being the appropriate instrument in the state and city plans. This illustrates a shared understanding between the different institutions in the country that planning has to be practical and specific when outlining how the objective needs to be achieved. It is also indicative of the maturity and durability of the German planning system, as observed by Münter and Reimer [60]. Similarly, the shared understanding of depopulation as a cross-cutting phenomenon affecting multiple policy and planning areas in The Netherlands appears to enable harmonization and mutual understanding between the different levels of the planning system as to what needs to be done and how the problem should be viewed, leaving only the details of the actual measures to be decided. This may also be indicative of the consensual nature of policymaking and politics in The Netherlands, as well as of the predictability and certainty of its planning system [61]. In contrast, the justifications and outlines of the different measures in Bilbao's plans are more widely contextualized but are less pragmatic.

Another difference in planning cultures is in their approaches to the housing market. In both Germany and The Netherlands, the impacts of depopulation on the housing market have been a key topic in planning and policy approaches. This can be observed in the frames as well as in the normative leaps. In the latter, however, there is a very clearly stated need to intervene in the housing market in order to balance the supply-demand mismatch. This approach may be indicative not only of planning culture differences but also of housing market characteristics. In both countries, public ownership of housing is quite high, as well as seeing the participation of large market players, such as housing companies, that may have had an influence on the examined policies and plans [62]. These circumstances put a greater responsibility on public authorities to manage the housing market, albeit with a limited capacity [63]. This is vastly different in Spain, where the housing is mostly free-market-driven and private ownership is higher; thus, any large-scale or radical market intervention is much more difficult. These conclusions align with the observations from previous research that planning cultures and systems have to be taken into account, particularly in the field of urban shrinkage, as they may have a critical role in determining possible courses of action $[64,65]$. These differences may also be particularly valid in the context of the COVID-19 pandemic and the ways in which cities can adapt to such changing circumstances.

\section{Conclusions}

The above interpretive policy analysis of framing and responses to urban shrinkage and depopulation uncovers the implicit or explicit interpretations and justifications that planners and policymakers have used to frame and approach the consequences of urban shrinkage and population decline. The insight on this aspect of planning and policymaking contributes to expanding the debates on urban shrinkage and depopulation by bringing them closer to planning and policy practices. Uncovering how the various aspects of shrinkage have been understood in practice can contribute to the development of solutions to shrinkage that are more sensitive to local contexts and may be perceived as more relevant by planners and policymakers in practice.

The empirical approach of analyzing planning and policy responses in an expanded institutional context, across the levels of the planning systems, illustrates the fact that shrinkage discussions may benefit from a broader planning perspective, with particular 
attention being paid to regional and economic planning and policymaking. This can ensure that discussions on causality and normative orientation should be more specific in identifying causes of shrinkage and depopulation. Furthermore, the results illustrate a more refined view of the dichotomy between the growth and non-growth normative orientation of planning and policies. Based on the conclusions herein, quality of life and (economic) growth orientation, as normative orientations and justifications, are not entirely mutually exclusive and they may be pursued as parallel planning objectives. The importance given to the quality of life is strongly dependent on planning cultures and planning systems, where more solidified views on the quality of life as a broader political goal may have a positive influence on planning efforts. These conclusions may also positively influence the discussions on alternative planning concepts for shrinkage, by bringing them closer to actual planning practice.

In terms of practical applicability, planning for shrinkage and depopulation needs to consider various scales and institutional settings, thereby engaging different actors in the planning system. The illustrated examples of consistent understanding between various policy levels demonstrate that this has had a positive effect on the identification of measures. Therefore, for future shrinking cities, it is important that the planning effort involves regional, state and national institutions in order to identify the most appropriate policy and planning approaches to the challenges that cities and regions will continue to face, especially in Europe. Such a broader approach should be adapted to the respective planning system and can also contribute to improvements in planning cultures.

Funding: This research is part of the RE-CITY ITN Project, which has received funding from the European Union's Horizon 2020 research and innovation program under the Marie Skłodowska-Curie grant, agreement No 813803.

Institutional Review Board Statement: Not applicable.

Informed Consent Statement: Not applicable.

Data Availability Statement: The majority of the analyzed documents are publicly accessible on the websites of the respective institutions, mentioned in the article. A list of the names of the documents and the websites they can be found below. Some of the documents are not publicly accessible and have been obtained through specific inquiry with the institutions in question. As a result, they have been received in electronic format or on paper by the author. They are not available upon request. Interview data has been anonymized and is neither publicly accessible nor available upon request. Bilbao Publicly available:

- $\quad$ Directrices para ordenacion del territorio 1997; Gobierno Vasco/Eusko Jaurlaritza; www.euskadi. eus (accessed on 8 March 2021).

- Plan Territorial Sectorial de Creación Pública de Suelo para Actividades Económicas y Equipamientos Comerciales 2005; Gobierno Vasco/Eusko Jaurlaritza; www.euskadi.eus (accessed on 8 March 2021)

- Plan Territorial Parcial Bilbao Metropolitano 2006; Gobierno Vasco/Eusko Jaurlaritza; www. euskadi.eus (accessed on 12 March 2021)

- PTP: Acciones estructurantes y estrategicas 2006; Gobierno Vasco/Eusko Jaurlaritza; www. euskadi.eus (accessed on 12 March 2021)

- PTP: Programa de Actuación y Estudio Económico Financiero 2006; Gobierno Vasco/Eusko Jaurlaritza (accessed on 12 March 2021)

- $\quad$ Bilbao The City where Dreams Come True-Strategic Reflection 1999; Bilbao Metropolí-30; www.bm30.eus (accessed on 8 March 2021)

- $\quad$ Bilbao as a Global City—Strategy 2001; Bilbao Metropolí-30; www.bm30.eus (accessed on 11 March 2021)

- Ahora, las Personas-Strategic Reflection 2005; Bilbao Metropolí-30; www.bm30.eus (accessed on 11 March 2021)

- $\quad$ Es tiempo de profesionales-Strategic Reflection 2010; Bilbao Metropolí-30; www.bm30.eus (accessed on 11 March 2021) 
- $\quad$ Plan General de Ordenacion Urbana de Bilbao 1995; Ayuntamento de Bilbao/Bilboko Udala; www.bilbao.eus (accessed on 9 March 2021)

- $\quad$ Plan Especial de Rehabilitación y reforma interior del área de Bilbao La Vieja 1994, Revised 2018; Ayuntamento de Bilbao/Bilboko Udala; www.bilbao.eus (accessed on 12 March 2021)

- $\quad$ Plan Especial de Reforma Interior de Ametzola 1995, Revised 2018; Ayuntamento de Bilbao/Bilboko Udala; www.bilbao.eus (accessed on 11 March 2021)

- Plan Parcial del Sector Miribilla ref. PGOU 2002; Ayuntamento de Bilbao/Bilboko Udala; www.bilbao.eus (accessed on 10 March 2021)

- $\quad$ Texto Refundido de la Modificacion del Plan Especial de Reforma Interior de Abandoibarra 1999, Revised 2010; Ayuntamento de Bilbao/Bilboko Udala; www.bilbao.eus (accessed on 8 March 2021)

- Resolución Plan Especial de Ordenación Urbana del Área Mixta de Zorrotzaurre 2012; Comisión Gestora para el Desarrollo Urbanístico de Zorrotzaurre/Zorrotzaurreko Hirigintza Garapenerako Batzorde Kudeatzailea; www.zorrotzaurre.com (accessed on 9 March 2021)

Leipzig

Publicly available:

- Statusbericht-Stadtumbau Ost 2006; BMI-Bundesministerium des Innern, für Bau und Heimat/Bundesministerium für Verkehr, Bau und Stadtentwicklung; www.bbsr.bund.de (accessed on 26 February 2021)

- $\quad$ Leipzig: 10 Jahre StadtumbauOst 2012; Stadt Leipzig; www.leipzig.de (accessed on 26 February 2021)

- $\quad$ Sachsen Landesentwicklungsplan 2003; Sächsisches Staatsministerium für Regionalentwicklung; www.landesentwicklung.sachsen.de (accessed on 25 February 2021)

- $\quad$ Stadtteile mit Besonderem Entwicklungsbedarf-Die Soziale Stadt 2005; Sächsisches Ministerium des Innern; www.dresden.de (accessed on 23 February 2021)

- $\quad$ Soziale Stadt Programbegleitung vor Ort im Modellgebiet Leipziger Osten 2002; Leipziger Osten-Quartiersmanagement; www.repository.difu.de (accessed on 23 February 2021)

- $\quad$ Soziale Stadt Evaluierung 2011 Leipziger Ost 2011; Stadt Leipzig; www.leipzig.de (accessed on 23 February 2021)

- $\quad$ Beiträge zur Stadtentwicklung 38: Stadtteilplan Leipziger Osten 2003; Stadt Leipzig; www. leipzig.de (accessed on 22 February 2021)

- $\quad$ Leipzig 2020 Integriertes Stadtentwicklungskonzept (SEKo) 2009; Stadt Leipzig; www.leipzig.de (accessed on 26 February 2021)

- $\quad$ SEKO Umsetzungsbericht 2012; Stadt Leipzig; leipzig.de (accesed on 26 February 2021)

- Integriertes Stadtteilentwicklungskonzept Leipziger Osten 2013; Stadt Leipzig; www.leipzig.de (accessed on 22 February 2021)

- $\quad$ Leipzig-Plagwitz-Broschüre-Entlassung-Sanierungsgebiet 2020; Stadt Leipzig; www.leipzig.de (accessed on 24 February 2021)

Not available publicly:

- Wirtschaft_Grundsatzpapier 2004; Staatsministerium für Wirtschaft, Arbeit und Verkehr

- Regionalplan Westsachsen 1998; Regionaler Planungsverband Leipzig-Westsachsen

- $\quad$ Wohnungspolitisches Konzept der Stadt Leipzig 2002; Stadt Leipzig

- $\quad$ Stadtentwicklungsplan Wohnungsbau Stadterneurung Teilplan Großsiedlungen 2002; Stadt Leipzig

- Stadtentwicklungsplan Wohnungsbau Stadterneurung Rahmenbedingungen, Teilplan Wohnungsbau, Teilplan Stadterneurung 2000; Stadt Leipzig

- $\quad$ Stadtentwicklungsplan Verkehr und Öffentlicher Raum 2004; Stadt Leipzig

- $\quad$ Stadtentwicklungsplan Gewerbliche Bauflächen 1999; Stadt Leipzig

- $\quad$ Stadtentwicklungsplan Gewerbliche Bauflächen Fortschreibung 2005; Stadt Leipzig

- $\quad$ Stadtentwicklungsplan Zentren 2000; Stadt Leipzig

The Netherlands/Zeeland

Publicly available

- $\quad$ Actieplan Bevolkingsdaling 2016; BZK-Ministerie van Binnenlandse Zaken en Koninkrijksrelaties; www.rijksoverheid.nl/onderwerpen/bevolkingsdaling (accessed on 4 May 2020)

- $\quad$ Eerste Voortgangsrapportage Bevolkingsdaling 2017; BZK-Ministerie van Binnenlandse Zaken en Koninkrijksrelaties; https://www.rijksoverheid.nl/onderwerpen/bevolkingsdaling (accessed on 4 May 2020) 
- $\quad$ Tweede Voortgangsrapportage Bevolkingsdaling 2018; BZK-Ministerie van Binnenlandse Zaken en Koninkrijksrelaties; https://www.rijksoverheid.nl/onderwerpen/bevolkingsdaling (accessed on 4 May2020)

- $\quad$ Derde Voortgangsrapportage Actieplan Bevolkingsdaling 2019; BZK-Ministerie van Binnenlandse Zaken en Koninkrijksrelaties; https://www.rijksoverheid.nl/onderwerpen/bevolkingsdaling (accessed on 4 May 2020)

- $\quad$ Regio Deal Zeeland 2018; Provincie Zeeland; www.rijksoverheid.nl (accessed on 7 May 2020)

- $\quad$ Zeeland in Stroomversnelling 2.0 2018; Provincie Zeeland; www.zeeland.nl (accessed on 6 May 2020)

- Kwaliteit en Onderscheidend Vermogen Kadernota Economische Agenda 2.0 2017; Provincie Zeeland; www.zeeland.nl (accessed on 6 May 2020)

- $\quad$ Onverkende Paden Uitdagingen voor de Provincie Zeeland Door de Veranderende Bevolkingsopbouw 2008; Provincie Zeeland; www.zeeland.nl (accessed on 6 May 2020)

- $\quad$ Plan van Aanpak Voor de Gevolgen van de Demografische Veranderingen in Zeeland 2010-2012 2009?; Provincie Zeeland; www.zeeland.nl (accessed on 4 May 2020)

- $\quad$ Nieuwe Wegen Nota Leefbaarheid and Bevolking 2014-2018; Provincie Zeeland; www.zeeland. $\mathrm{nl}$ (accessed on 5 May 2020)

- $\quad$ The path ahead-Zeeland; Provincie Zeeland; www.zeeland.nl (accessed on 5 May 2020)

Conflicts of Interest: The author declares no conflict of interest. The funders had no role in the design of the study; in the collection, analyses, or interpretation of data; in the writing of the manuscript, or in the decision to publish the results.

\section{References}

1. Kondratieff, N.D.; Stolper, W.F. The Long Waves in Economic Life. Rev. Econ. Stat. 1935, 17, 105. [CrossRef]

2. Molotch, H. The City as a Growth Machine: Toward a Political Economy of Place. Am. J. Sociol. 1976, 82, 309-332. [CrossRef]

3. Oswalt, P.; Schirmel, H. Atlas of Shrinking Cities; Hatje Cantz: Ostfildern, Germany, 2006.

4. Turok, I.; Mykhnenko, V. Resurgent European cities? Urban Res. Pr. 2008, 1, 54-77. [CrossRef]

5. Swyngedouw, E. Globalisation or 'glocalisation'? Networks, territories and rescaling. Hist. Econ. Soc. Bull. 2004, 17, 25-48. [CrossRef]

6. Martinez-Fernandez, C.; Audirac, I.; Fol, S.; Cunningham-Sabot, E. Shrinking Cities: Urban Challenges of Globalization. Int. J. Urban Reg. Res. 2012, 36, 213-225. [CrossRef]

7. Wolff, M.; Wiechmann, T. Urban growth and decline: Europe's shrinking cities in a comparative perspective 1990-2010. Eur. Urban Reg. Stud. 2018, 25, 122-139. [CrossRef]

8. Rychtarikova, J. Is Eastern Europe Experiencing a Second Demographic Transition? Geography 1999, 1, $19-44$.

9. Bontje, M.; Musterd, S. Understanding Shrinkage in European Regions. Built Environ. 2012, 38, 153-161. [CrossRef]

10. Wiechmann, T.; Pallagst, K.M. Urban shrinkage in Germany and the USA: A Comparison of Transformation Patterns and Local Strategies. Int. J. Urban Reg. Res. 2012, 36, 261-280. [CrossRef]

11. Ortiz-Moya, F. Coping with shrinkage: Rebranding post-industrial Manchester. Sustain. Cities Soc. 2015, 15, 33-41. [CrossRef]

12. Wiechmann, T. Conversion Strategies under Uncertainty in Post-Socialist Shrinking Cities: The example of Dresden in Eastern Germany. In The Future of Shrinking Cities: Problems, Patterns and Strategies of Urban Transformation in a Global Context; University of California: Los Angeles, CA, USA, 2009; pp. 5-16.

13. Stryjakiewicz, T.; Jaroszewska, E. The Process of Shrinkage as a Challenge to Urban Governance. Quaest. Geogr. 2016, 35, 27-37. [CrossRef]

14. Hospers, G.J. Policy Responses to Urban Shrinkage: From Growth Thinking to Civic Engagement. Eur. Plan. Stud. 2014, 22, 1507-1523. [CrossRef]

15. Radzimski, A. View Web of Science ResearcherID and ORCID (provided by Clarivate). Cities 2016, 50, 197-205. [CrossRef]

16. Rall, E.L.; Haase, D. Creative intervention in a dynamic city: A sustainability assessment of an interim use strategy for brownfields in Leipzig, Germany. Landsc. Urban Plan. 2011, 100, 189-201. [CrossRef]

17. Aber, J.; Yahagi, H. Emerging Regeneration Strategies in the US, Europe and Japan. In Shrinking cities. International Perspectives and Policy Implications; Routledge: New York, NY, USA, 2014; pp. 257-279.

18. Sánchez-Moral, S. The mobility of 'creative workers' and their potential contribution to the recovery of old industrial cities in Spain. Town Plan. Rev. 2017, 88, 93-107. [CrossRef]

19. Rink, D.; Haase, A.; Grossmann, K.; Couch, C.; Cocks, M. From Long-Term Shrinkage to Re-Growth? The Urban Development Trajectories of Liverpool and Leipzig. Built Environ. 2012, 38, 162-178. [CrossRef]

20. Schatz, L. Going for growth and managing decline: The complex mix of planning strategies in Broken Hill, NSW, Australia. Town Plan. Rev. 2017, 88, 43-57. [CrossRef]

21. Sousa, S.; Pinho, P. Planning for Shrinkage: Paradox or Paradigm. Eur. Plan. Stud. 2015, 23, 12-32. [CrossRef]

22. Hollander, J.; Pallagst, K.; Schwarz, T.; Popper, F. Planning shrinking cities. Prog. Plan. 2009, 72, $223-232$.

23. Hartt, M. The Elasticity of Shrinking Cities: An Analysis of Indicators. Prof. Geogr. 2021, 73, 230-239. [CrossRef]

24. Ganning, J.P.; Tighe, J.R. Moving toward a Shared Understanding of the U.S. Shrinking City. J. Plan. Educ. Res. 2021, 41, 188-201. [CrossRef] 
25. Hirt, S.; Beauregard, R. Must shrinking cities be distressed cities? A historical and conceptual critique. Int. Plan. Stud. 2021, 26, 1-13. [CrossRef]

26. Berglund, L. Critiques of the Shrinking Cities Literature from an Urban Political Economy Framework. J. Plan. Lit. 2020, 35, 423-439. [CrossRef]

27. Bernt, M. The Limits of Shrinkage: Conceptual Pitfalls and Alternatives in the Discussion of Urban Population Loss. Int. J. Urban Reg. Res. 2015, 40, 441-450. [CrossRef]

28. Haase, A.; Rink, D.; Grossmann, K.; Bernt, M.; Mykhnenko, V. Conceptualizing Urban Shrinkage. Environ. Plan. A Econ. Space 2014, 46, 1519-1534. [CrossRef]

29. Olsen, A.K. Shrinking Cities: Fuzzy Concept or Useful Framework? Berkeley Plan. J. 2013, 26, 107-132. [CrossRef]

30. Bernt, M.; Haase, A.; Großmann, K.; Cocks, M.; Couch, C.; Cortese, C.; Krzysztofik, R. How does(n't) Urban Shrinkage get onto the Agenda? Experiences from Leipzig, Liverpool, Genoa and Bytom. Int. J. Urban Reg. Res. 2014, 38, 1749-1766. [CrossRef]

31. Fischer, F. Reframing Public Policy: Discursive Politics and Deliberative Practices; Oxford University Press: Oxford, UK, 2003.

32. Markusen, A. Fuzzy Concepts, Scanty Evidence, Policy Distance: The Case for Rigour and Policy Relevance in Critical Regional Studies. Reg. Stud. 1999, 33, 869-884. [CrossRef]

33. Haase, A.; Bernt, M.; Großmann, K.; Mykhnenko, V.; Rink, D. Varieties of shrinkage in European cities. Eur. Urban Reg. Stud. 2016, 23, 86-102. [CrossRef]

34. Fischer, F.; Forester, J. The Argumentative Turn in Policy Analysis and Planning, 2nd ed.; Duke University Press: Durham, NC, USA, 1996.

35. Hajer, M. Discourse analysis and the study of policy making. Eur. Politi.-Sci. 2002, 2, 61-65. [CrossRef]

36. Asdal, K. What is the issue? The transformative capacity of documents. Distinktion J. Soc. Theory 2015, 16, 74-90. [CrossRef]

37. Jacobs, K. Discourse Analysis and its Utility for Urban Policy Research. Urban Policy Res. 2006, 24, 39-52. [CrossRef]

38. Healey, P. Collaborative Planning: Shaping Places in Fragmented Societies (Planning, Environment, Cities), 2nd ed.; Palgrave Macmillan: Basingstoke, UK, 2006.

39. Batty, M. Science in Planning: Theory, Methods and Models. In Planning Knowledge and Research; Routledge: New York, NY, USA, 2018; pp. 241-254.

40. Rein, M.; Schön, D. Reframing Policy Discourse. In The Argumentative Turn in Policy Analysis and Planning, 2nd ed.; Duke University Press: Durham, NC, USA, 1996; pp. 145-167.

41. Stone, D.A. Policy Paradox: The Art of Political Decision Making; Revised ed.; Norton: New York, NY, USA, 2002.

42. Fay, B. Contemporary Philosophy of Social Science: A Multicultural Approach; Blackwell: Oxford, UK, 1996.

43. Rodriguez, A.; Martinez, E. Del Declive a la Revitalización: Oportunidades y Límites de las Nuevas Políticas Urbanas en Bilbao. CIUDAD Y TERRITORIO. Estudios Territoriales. 2001, XXXIII, pp. 441-459. Available online: https://recyt.fecyt.es/index.php/ CyTET/article/view/75048 (accessed on 25 September 2021).

44. Plaza, B. The Return on Investment of the Guggenheim Museum Bilbao. Int. J. Urban Reg. Res. 2006, 30, 452-467. [CrossRef]

45. Couch, C.; Karecha, J.; Nuissl, H.; Rink, D. Decline and sprawl: An evolving type of urban development-observed in Liverpool and Leipzig. Eur. Plan. Stud. 2005, 13, 117-136. [CrossRef]

46. Bontje, M. Facing the challenge of shrinking cities in East Germany: The case of Leipzig. GeoJournal 2004, 61, 13-21. [CrossRef]

47. Elzerman, K.; Bontje, M. Urban Shrinkage in Parkstad Limburg. Eur. Plan. Stud. 2015, 23, 87-103. [CrossRef]

48. Beunen, R.; Meijer, M.; de Vries, J. Planning strategies for dealing with population decline: Experiences from The Netherlands. Land Use Policy 2020, 93, 104107. [CrossRef]

49. Verwest, F. Demographic Decline and Local Government Strategies: A Study of Policy Change in The Netherlands; Eburon: Delft, The Netherlands, 2011.

50. Uranga, M.G.; Etxebarria, G. Panorama of the Basque Country and its Competence for Self-Government. Eur. Plan. Stud. 2000, 8, 521-535. [CrossRef]

51. Reimer, M.; Getimis, P.; Blotevogel, H. Spatial Planning Systems and Practices in Europe: A Comparative Perspective on Continuity and Changes; Routledge: New York, NY, USA, 2014.

52. Haartsen, T.; Venhorst, V. Planning for Decline: Anticipating on Population Decline in The Netherlands. Tijdschr. Econ. Soc. Geogr. 2010, 101, 218-227. [CrossRef]

53. González, S. Scalar Narratives in Bilbao: A Cultural Politics of Scales Approach to the Study of Urban Policy. Int. J. Urban Reg. Res. 2006, 30, 836-857. [CrossRef]

54. Bernt, M. Partnerships for Demolition: The Governance of Urban Renewal in East Germany's Shrinking Cities. Int. J. Urban Reg. Res. 2009, 33, 754-769. [CrossRef]

55. Hollander, J.B. Can a City Successfully Shrink? Evidence from Survey Data on Neighborhood Quality. Urban Aff. Rev. 2010, 47, 129-141. [CrossRef]

56. Haase, A.; Bontje, M.; Couch, C.; Marcinczak, S.; Rink, D.; Rumpel, P.; Wolff, M. Factors driving the regrowth of European cities and the role of local and contextual impacts: A contrasting analysis of regrowing and shrinking cities. Cities 2021, 108, 102942. [CrossRef]

57. Knaap, G.; Talen, E. New Urbanism and Smart Growth: A Few Words from the Academy. Int. Reg. Sci. Rev. 2005, 28, 107-118. [CrossRef]

58. Edwards, M.M.; Haines, A. Evaluating Smart Growth. J. Plan. Educ. Res. 2007, 27, 49-64. [CrossRef]

59. Khan, A.Z.; Moulaert, F.; Schreurs, J.; Miciukiewicz, K. Integrative Spatial Quality: A Relational Epistemology of Space and Transdisciplinarity in Urban Design and Planning. J. Urban Des. 2014, 19, 393-411. [CrossRef] 
60. Münter, A.; Reimer, M. Planning Systems on the Move? Persistence and Change of the German Planning System. Plan. Pr. Res. 2020, 1-19. [CrossRef]

61. Newman, P.; Thornley, A. Urban Planning in Europe: International Competition, National Systems, and Planning Projects; Routledge: London, UK, 1996.

62. Bernt, M. The emergence of "Stadtumbau Ost". Urban Geogr. 2017, 40, 174-191. [CrossRef]

63. Hoekstra, M.S.; Hochstenbach, C.; Bontje, M.; Musterd, S. Shrinkage and housing inequality: Policy responses to population decline and class change. J. Urban Aff. 2020, 42, 333-350. [CrossRef]

64. Pallagst, K.; Fleschurz, R.; Said, S. What drives planning in a shrinking city? Tales from two German and two American cases. Town Plan. Rev. 2017, 88, 15-28. [CrossRef]

65. Pallagst, K. Viewpoint: The planning research agenda: Shrinking cities-A challenge for planning cultures. Town Plan. Rev. 2010, 81, 1-6. [CrossRef] 